\title{
CONJUNÇÕES ADVERSATIVAS DO PORTUGUÊS
}

\author{
Afrânio da Silva Garcia (UERJ) \\ afraniogarcia@gmail.com
}

\section{Introdução}

O objetivo deste trabalho foi o de fazer um levantamento das conjunções adversativas do português contemporâneo e das diferenças porventura existentes entre elas. Para tanto, não nos limitamos simplesmente a quantificar a ocorrência dessa ou daquela conjunção, mas tentamos delimitar o tipo de ambiente em que elas ocorrem e a nuance significativa que cada uma delas transmite, a partir de determinados fatores sintáticos e semânticos, que serão objeto de discussão na próxima seção do trabalho.

Resolvemos utilizar como "corpus" do trabalho três livros de um dos mais consagrados autores brasileiros contemporâneos, aclamado tanto pela crítica especializada quanto pelo público em geral: João Ubaldo Ribeiro. As obras escolhidas foram: Sargento Getúlio, representativa de uma linguagem bastante descuidada e informal, característica do personagem-narrador e da maneira como é narrada a história, através do fluxo de consciência; Livro de histórias, com uma linguagem bem mais cuidada e formal; e Política, com uma linguagem extremamente cuidada e formal, característica do discurso didático e científico.

Quanto à originalidade e à validade do trabalho, acreditamos que qualquer tentativa séria de se precisar quais são as características distintivas das conjunções adversativas seria de extrema valia para o progresso dos estudos linguísticos do português, não só por se tratar de uma pesquisa nova (ao que se saiba, não existe praticamente nenhuma pesquisa já feita ou em vias de conclusão sobre o assunto) como também por lidar com uma parte tão importante para a comunicação, como é o caso das conjunções adversativas. 


\section{Fatores semânticos e sintáticos}

\subsection{Função coordenativa e função coesiva}

O primeiro fator a se considerar ao analisarmos as conjunções adversativas é verificar se elas estão desempenhando uma função coordenativa, ou seja, se elas estão relacionando orações pertencentes a um mesmo período, ou se elas estão desempenhando uma função coesiva, isto é, se elas estão relacionando partes maiores do discurso, como períodos ou parágrafos. A partir daí, poderemos definir se a função desta ou daquela conjunção adversativa é, prioritariamente ou exclusivamente, juntar orações ou juntar períodos ou parágrafos.

Parece-nos óbvio que uma subdivisão das conjunções com função coesiva faz-se necessária a partir desta distinção: aquelas que introduzem no discurso um novo período e aquelas que introduzem no discurso um novo parágrafo, visto um parágrafo ser uma unidade textual muito mais ampla do que um simples período.

Para uma definição do que sejam coesão e função coesiva, recomendamos a leitura da introdução do livro Cohesion in English, de Halliday e Hasan (p. 1-30).

\subsection{Posição na frase}

Um segundo fator a se considerar seria a posição das conjunções adversativas no interior da frase, de modo a delimitar quais as que ocorrem preferencialmente, ou sempre, em posição inicial e quais as que ocorrem preferencialmente, ou sempre, em posição não inicial. No segundo caso, seria interessante, igualmente, verificar-se quais ocorrem em posição medial e quais ocorrem em posição final.

\subsection{Mesma polaridade ou polaridades distintas}

O terceiro fator a se levar em conta é se a sentença introduzida pela conjunção adversativa tem a mesma polaridade que a sentença precedente ou se ambas têm polaridades distintas. Polaridade equivaleria à tradicional divisão das sentenças em afirmativas e negativas (cf. Cohesion in English, de Halliday e Hasan, p. 176). 


\subsection{Tipo de relação de sentido}

Um quarto fator a ser considerado seria o tipo de relação de sentido que se estabelece entre a oração, período ou parágrafo que contém a conjunção adversativa e a oração, período ou parágrafo a que a conjunção adversativa remete. Distinguimos três tipos básicos de relação de sentido:

a) Oposição pura e simples - em que o sentido de uma determinada porção do texto se opõe ao de outra, sem maiores complicações, como no exemplo abaixo.

1) Alípio queria falar, mas não podia,... (Sargento Getúlio, p. 15)

b) Oposição ao esperado - em que o sentido de uma determinada porção do texto se opõe ao que seria de se esperar a partir de uma outra porção do texto, como no exemplo que se segue.

2) Então se deu-se que a velha comeu o macaco mas o macaco saiu inteiro,... (op. cit., p. 105)

c) Restrição - em que uma determinada porção do texto se opõe a outra de uma maneira incompleta, como que restringindo o que fora dito anteriormente, como no exemplo abaixo.

3) Verdade que tem certos velhos que ainda são machos, mas esses é do tempo antigo, não é de hoje. (op. cit., p. 122)

Além desses, encontramos algumas ocorrências de partes do texto introduzidas por orações adversativas que não se enquadravam em nenhum dos tipos acima, as quais foram reunidas sob a denominação outros.

\subsection{Tipo de junção}

O último fator a ser estudado na nossa pesquisa das conjunções adversativas foi o tipo de junção entre o segmento de discurso que contém a conjunção adversativa e o segmento de discurso a que a conjunção adversativa remete. Consideramos de suma importância o fato de essa junção ser correlativa ou não.

Junção correlativa seria aquela em que as duas partes do discurso estivessem de tal forma associadas que a primeira, dita prótase, prenunciaria a segunda, dita apódose. É importante notar, no entanto, que o fato de a prótase preparar a apódose ou de a apódose ser a conclusão lógica e 
necessária do pensamento expresso pela prótase não implica, necessariamente, numa sequenciação temporal, como podemos ver no seguinte exemplo.

(4) É não só bravo mas hábil. (CÂMARA JR., 1981, p. 87)

Dividimos, portanto, as orações, períodos e parágrafos introduzidos por conjunção adversativa em dois tipos: aqueles que implicam uma junção correlativa e aqueles que implicam uma junção não correlativa.

\section{Resultados da pesquisa}

\subsection{Resultados gerais da pesquisa}

Antes de estudarmos os resultados específicos da pesquisa, com relação a cada conjunção adversativa, vale a pena dar uma olhada nos resultados gerais da pesquisa.

Foram encontradas 906 conjunções adversativas, distribuídas da seguinte maneira:

\begin{tabular}{|l|l|l|}
\hline CONJUNÇÃO & No DE OCORRÊNCIAS $^{\circ}$ PORCENTAGEM \\
\hline Mas & 847 & $93,49 \%$ \\
\hline Contudo & 24 & $2,65 \%$ \\
\hline Entretanto & 16 & $1,77 \%$ \\
\hline Porém & 15 & $1,65 \%$ \\
\hline No entanto & 4 & $0,44 \%$ \\
\hline
\end{tabular}

Em Sargento Getúlio, o livro cuja linguagem busca reproduzir o modo de falar descuidado e cheio de regionalismos do povo, foram encontradas 333 conjunções adversativas, distribuídas do seguinte modo:

\begin{tabular}{|l|l|l|}
\hline CONJUNÇÃO & No DE OCORRÊNCIAS $^{\circ}$ PORCENTAGEM \\
\hline Mas & 328 & $98,5 \%$ \\
\hline Porém & 4 & $1,2 \%$ \\
\hline Entretanto & 1 & $0,3 \%$ \\
\hline
\end{tabular}

Em Livro de histórias, expresso numa linguagem mais cuidada, embora coloquial, foram encontradas 378 conjunções adversativas, dispostas da seguinte forma: 


\begin{tabular}{|l|l|l|}
\hline Conjunção & $\mathrm{N}^{\mathbf{o}}$ de Ocorrências & Porcentagem \\
\hline Mas & 360 & $95,26 \%$ \\
\hline Porém & 10 & $2,64 \%$ \\
\hline Entretanto & 5 & $1,32 \%$ \\
\hline Contudo & 2 & $0,52 \%$ \\
\hline No entanto & 1 & $0,26 \%$ \\
\hline
\end{tabular}

Em Política, expresso na linguagem técnico-científica, altamente cuidada, ocorreram 195 conjunções adversativas, de acordo com a seguinte ordem:

\begin{tabular}{|l|l|l|}
\hline Conjunção & $\mathrm{N}^{\mathbf{o}}$ de Ocorrências & Porcentagem \\
\hline Mas & 159 & $81,54 \%$ \\
\hline Contudo & 22 & $11,28 \%$ \\
\hline Entretanto & 10 & $5,13 \%$ \\
\hline No entanto & 3 & $1,54 \%$ \\
\hline Porém & 1 & $0,51 \%$ \\
\hline
\end{tabular}

Com relação ao tipo de função, tivemos os seguintes resultados, considerando-se o total de 906 conjunções:

\begin{tabular}{|l|l|l|}
\hline Tipo de Função & $\mathrm{N}^{\circ}$ de Ocorrências & Porcentagem \\
\hline Coordenativa & 627 & $69,2 \%$ \\
\hline Coesiva & 279 & $30,8 \%$ \\
\hline - introduz período & 247 & $27,26 \%$ \\
\hline - introduz parágrafo & 32 & $3,54 \%$ \\
\hline
\end{tabular}

Em Sargento Getúlio, os resultados foram os seguintes, para um total de 333 conjunções:

\begin{tabular}{|l|l|l|}
\hline Tipo de função & $\mathrm{N}^{\mathbf{o}}$ de Ocorrências & Porcentagem \\
\hline Coordenativa & 239 & $71,77 \%$ \\
\hline Coesiva & 94 & $28,23 \%$ \\
\hline - introduz período & 91 & $27,32 \%$ \\
\hline - introduz parágrafo & 3 & 0,91 \\
\hline
\end{tabular}

Em Livro de histórias, tivemos os resultados abaixo, para um total de 378 conjunções:

\begin{tabular}{|l|l|l|}
\hline Tipo de Função & $\mathrm{N}^{\circ}$ de Ocorrências & Porcentagem \\
\hline Coordenativa & 277 & $73,28 \%$ \\
\hline Coesiva & 101 & $26,72 \%$ \\
\hline - introduz período & 84 & $22,22 \%$ \\
\hline - introduz parágrafo & 17 & $4,50 \%$ \\
\hline
\end{tabular}

Em Política, os resultados foram como se segue, para um total de 195 conjunções: 
DEPARTAMENTO DE LETRAS

\begin{tabular}{|l|l|l|}
\hline Tipo de Função & $\mathrm{N}^{\circ}$ de Ocorrências & Porcentagem \\
\hline Coordenativa & 112 & $57,43 \%$ \\
\hline Coesiva & 83 & $42,57 \%$ \\
\hline - introduz período & 72 & $36,92 \%$ \\
\hline - introduz parágrafo & 11 & 5,65 \\
\hline
\end{tabular}

Com relação à posição na frase, tivemos os seguintes resultados, para um total de 906 ocorrências:

\begin{tabular}{|l|l|l|}
\hline Posição & $\mathrm{N}^{\circ}$ de Ocorrências & Porcentagem \\
\hline Começo de frase & 890 & $98,23 \%$ \\
\hline Meio de frase & 16 & $1,77 \%$ \\
\hline
\end{tabular}

Devido ao número reduzidíssimo de ocorrências de conjunção adversativa em meio de frase (não havendo sequer uma ocorrência de conjunção adversativa em fim de frase), deixaremos para estudá-las mais adiante, quando abordarmos cada conjunção isoladamente.

Com relação à polaridade, tivemos os seguintes resultados gerais, para um total de 906 ocorrências:

\begin{tabular}{|l|l|l|}
\hline Tipo de Polaridade & $\mathrm{N}^{\mathrm{o}}$ de Ocorrências & Porcentagem \\
\hline Mesma polaridade & 532 & $58,72 \%$ \\
\hline Polaridades distintas & 374 & $41,28 \%$ \\
\hline
\end{tabular}

Em Sargento Getúlio, os resultados foram os que se seguem, para um total de 333 ocorrências:

\begin{tabular}{|l|l|l|}
\hline Tipo de Polaridade & $\mathrm{N}^{\mathrm{o}}$ de Ocorrências & Porcentagem \\
\hline Mesma polaridade & 174 & $52,25 \%$ \\
\hline Polaridades distintas & 159 & $47,75 \%$ \\
\hline
\end{tabular}

Em Livro de histórias, os resultados foram os seguintes, para um total de 378 ocorrências:

\begin{tabular}{|l|l|l|}
\hline Tipo de Polaridade & $\mathrm{N}^{\mathbf{o}}$ de Ocorrências & Porcentagem \\
\hline Mesma polaridade & 249 & $65,87 \%$ \\
\hline Polaridades distintas & 129 & $34,13 \%$ \\
\hline
\end{tabular}

m Política, chegamos aos seguintes resultados, para um total de 195 ocorrências:

\begin{tabular}{|l|l|l|}
\hline Tipo de Polaridade & $\mathrm{N}^{\mathbf{o}}$ de Ocorrências & Porcentagem \\
\hline Mesma polaridade & 110 & $56,41 \%$ \\
\hline Polaridades distintas & 85 & $43,59 \%$ \\
\hline
\end{tabular}

No que concerne ao tipo de relação de sentido, tivemos os seguintes resultados gerais, para um total de 906 conjunções adversativas: 


\begin{tabular}{|l|l|l|}
\hline Relação de Sentido & $\mathrm{N}^{\circ}$ de Ocorrências & Porcentagem \\
\hline Oposição & 576 & $63,57 \%$ \\
\hline Oposição ao esperado & 119 & $13,13 \%$ \\
\hline Restrição & 176 & $19,43 \%$ \\
\hline Outros & 35 & $3,87 \%$ \\
\hline
\end{tabular}

Em Sargento Getúlio, chegamos aos resultados abaixo, para um total de 333 ocorrências:

\begin{tabular}{|l|l|l|}
\hline Relação de Sentido & $\mathrm{N}^{\circ}$ de Ocorrências & Porcentagem \\
\hline Oposição & 182 & $54,65 \%$ \\
\hline Oposição ao esperado & 67 & $20,12 \%$ \\
\hline Restrição & 66 & $19,82 \%$ \\
\hline Outros & 18 & $5,41 \%$ \\
\hline
\end{tabular}

Em Livro de histórias, os resultados foram os que se seguem, para um total de 378 ocorrências:

\begin{tabular}{|l|l|l|}
\hline Relação de Sentido & $\mathrm{N}^{\mathrm{o}}$ de Ocorrências & Porcentagem \\
\hline Oposição & 287 & $75,92 \%$ \\
\hline Oposição ao esperado & 43 & $11,37 \%$ \\
\hline Restrição & 36 & $9,52 \%$ \\
\hline Outros & 12 & $3.19 \%$ \\
\hline
\end{tabular}

Em Política, atingimos os seguintes resultados. Para um total de 195 ocorrências:

\begin{tabular}{|l|l|l|}
\hline Relação de Sentido & $\mathrm{N}^{\circ}$ de Ocorrências & Porcentagem \\
\hline Oposição & 107 & $54.87 \%$ \\
\hline Oposição ao esperado & 9 & $4.61 \%$ \\
\hline Restrição & 73 & $37.43 \%$ \\
\hline Outros & 6 & $3.09 \%$ \\
\hline
\end{tabular}

Por último, tivemos os seguintes resultados gerais com relação ao tipo de junção, para um total de 906 ocorrências:

\begin{tabular}{|l|l|l|}
\hline Tipo de Junção & $\mathrm{N}^{\mathbf{o}}$ de Ocorrências & Porcentagem \\
\hline Correlativa & 125 & $13.79 \%$ \\
\hline Não correlativa & 781 & $86.21 \%$ \\
\hline
\end{tabular}

Em Sargento Getúlio, os resultados foram os seguintes, para 333 ocorrências:

\begin{tabular}{|l|l|l|}
\hline Tipo de Junção & $\mathrm{N}^{\mathbf{o}}$ de Ocorrências & Porcentagem \\
\hline Correlativa & 39 & $11.71 \%$ \\
\hline Não correlativa & 294 & $88.29 \%$ \\
\hline
\end{tabular}


Em Livro de histórias, obtivemos os seguintes resultados, para um total de 378 ocorrências:

\begin{tabular}{|l|l|l|}
\hline Tipo de Junção & $\mathrm{N}^{\mathbf{o}}$ de Ocorrências & Porcentagem \\
\hline Correlativa & 33 & $8.73 \%$ \\
\hline Não correlativa & 345 & $91.27 \%$ \\
\hline
\end{tabular}

Em Política, chegamos aos resultados abaixo, para um total de 195 ocorrências:

\begin{tabular}{|l|l|l|}
\hline Tipo de Junção & $\mathrm{N}^{\mathbf{o}}$ de Ocorrências & Porcentagem \\
\hline Correlativa & 52 & $26,67 \%$ \\
\hline Não correlativa & 143 & $73,33 \%$ \\
\hline
\end{tabular}

Com base no que foi observado nos resultados gerais da pesquisa, podemos afirmar que:

a) A menos que o escritor João Ubaldo Ribeiro se desvie profundamente da norma padrão do português contemporâneo do Brasil, pode-se dizer que a conjunção todavia não é produtiva (ou é muito pouco produtiva) na modalidade brasileira do português nos dias de hoje.

b) A supremacia da conjunção mas sobre as demais é incontestável (entre $98,5 \%$ e $81,5 \%)$.

c) A locução conjuntiva no entanto é muito pouco usada no português de ultramar (entre $0,0 \%$ e $1,5 \%$ ).

d) As conjunções porém e contudo se comportam de maneira diametralmente oposta com relação ao tipo de linguagem empregado: quanto mais cuidada é a linguagem, mais se usa contudo e menos se usa porém, e vice-versa.

e) Igualmente, quanto mais cuidada é a linguagem, tanto mais se usam as conjunções adversativas com função coesiva.

f) $\mathrm{O}$ uso de conjunções adversativas em meio de frase é extremamente raro $(0,67 \%)$.

g) Ao que parece, o fato de o segmento de discurso introduzido pela conjunção adversativa ter ou não a mesma polaridade da oração ou sentença precedente não é relevante (entre $52,2 \%$ e $65,9 \%$ dos casos, a polaridade é idêntica).

h) No que concerne às relações de sentido, embora a oposição pura e simples seja a mais frequente sempre, a taxa de uso de orações que ex- 
pressam restrição vai aumentando conforme a linguagem passa a ser mais cuidada (de $19,8 \%$ para $37,4 \%$ ).

i) Já a taxa de uso de orações que expressam oposição ao esperado sofre o efeito inverso: quanto mais cuidada a linguagem, tanto menos ocorrem tais orações (de $20,1 \%$ para $4,6 \%$ ).

j) No que diz respeito ao tipo de junção, a junção não correlativa é muito mais frequente, embora a junção correlativa torne-se bastante frequente $(26,7 \%)$ na linguagem didático-científica.

Nas seções seguintes, estudaremos cada conjunção isoladamente, de modo a verificar se o tipo de conjunção empregado influencia os números acima.

\subsection{Mas}

Foram encontradas 847 ocorrências da conjunção mas, as quais correspondem a 93,48\% do total, sendo 360 em Livro de histórias (correspondendo a 95,23\%), 328 em Sargento Getúlio (equivalendo a 98,49\%) e 159 em Política (totalizando 81,53\%). Como podemos notar, ocorre um decréscimo bastante significativo na sua taxa de frequência quando se emprega a linguagem didático-científica.

Com relação ao tipo de função desempenhado pela conjunção adversativa, chegamos aos seguintes resultados:

GERAL (847 ocorrências)

\begin{tabular}{|l|l|l|}
\hline Tipo de Função & $\mathrm{N}^{\circ}$ de Ocorrências & Porcentagem \\
\hline Coordenativa & 618 & $72,96 \%$ \\
\hline Coesiva & 229 & $27,04 \%$ \\
\hline - introduz período & 209 & $24,67 \%$ \\
\hline - introduz parágrafo & 20 & $2,37 \%$ \\
\hline
\end{tabular}

SARGENTO GETÚLIO (328 ocorrências)

\begin{tabular}{|l|l|l|}
\hline Tipo de Função & $\mathrm{N}^{\mathbf{o}}$ de Ocorrências & Porcentagem \\
\hline Coordenativa & 236 & $71,95 \%$ \\
\hline Coesiva & 92 & $28,05 \%$ \\
\hline - introduz período & 89 & $27,13 \%$ \\
\hline - introduz parágrafo & 3 & 0,92 \\
\hline
\end{tabular}


LIVRO DE HISTÓRIAS (360 ocorrências)

\begin{tabular}{|l|l|l|}
\hline Tipo de Função & $\mathrm{N}^{\circ}$ de Ocorrências & Porcentagem \\
\hline Coordenativa & 272 & $75,55 \%$ \\
\hline Coesiva & 88 & $24,45 \%$ \\
\hline - introduz período & 76 & $21,11 \%$ \\
\hline - introduz parágrafo & 12 & $3,34 \%$ \\
\hline
\end{tabular}

POLÍTICA (159 ocorrências)

\begin{tabular}{|l|l|l|}
\hline Tipo de Função & $\mathrm{N}^{\mathbf{o}}$ de Ocorrências & Porcentagem \\
\hline Coordenativa & 110 & $69,18 \%$ \\
\hline Coesiva & 49 & $30,82 \%$ \\
\hline - introduz período & 44 & $27,67 \%$ \\
\hline - introduz parágrafo & 5 & $3,15 \%$ \\
\hline
\end{tabular}

Com relação à posição na frase, não houve sequer um exemplo de utilização da conjunção mas em posição não inicial na oração. Além disso, tal uso soa por demais estranho, impossível mesmo no estágio atual da nossa língua.

Com relação à polaridade, chegou-se aos seguintes resultados:

GERAL (847 ocorrências)

\begin{tabular}{|l|l|l|}
\hline Tipo de Polaridade & $\mathrm{N}^{\mathbf{o}}$ de Ocorrências & Porcentagem \\
\hline Mesma polaridade & 492 & $58,09 \%$ \\
\hline Polaridades distintas & 355 & $41,91 \%$ \\
\hline
\end{tabular}

SARGENTO GETÚLIO (328 ocorrências)

\begin{tabular}{|l|l|l|}
\hline Tipo de Polaridade & $\mathrm{N}^{\mathbf{o}}$ de Ocorrências & Porcentagem \\
\hline Mesma polaridade & 170 & $51,82 \%$ \\
\hline Polaridades distintas & 158 & $48,18 \%$ \\
\hline
\end{tabular}

LIVRO DE HISTÓRIAS (360 ocorrências).

\begin{tabular}{|l|l|l|}
\hline Tipo de Polaridade & $\mathrm{N}^{\mathbf{o}}$ de Ocorrências & Porcentagem \\
\hline Mesma polaridade & 238 & $66,11 \%$ \\
\hline Polaridades distintas & 122 & $33,89 \%$ \\
\hline
\end{tabular}

POLÍTICA (159 ocorrências).

\begin{tabular}{|l|l|l|}
\hline Tipo de Polaridade & $\mathrm{N}^{\mathbf{o}}$ de Ocorrências & Porcentagem \\
\hline Mesma polaridade & 84 & $52,83 \%$ \\
\hline Polaridades distintas & 75 & $47,17 \%$ \\
\hline
\end{tabular}

Com relação ao tipo de relação de sentido, chegou-se aos seguintes resultados: 
GERAL (847 ocorrências).

\begin{tabular}{|l|l|l|}
\hline Relação de Sentido & $\mathrm{N}^{\circ}$ de Ocorrências & Porcentagem \\
\hline Oposição & 571 & $67,41 \%$ \\
\hline Oposição ao esperado & 109 & $12,87 \%$ \\
\hline Restrição & 132 & $15,58 \%$ \\
\hline Outros & 35 & $4,14 \%$ \\
\hline
\end{tabular}

SARGENTO GETÚLIO (328 ocorrências).

\begin{tabular}{|l|l|l|}
\hline Relação de Sentido & $\mathrm{N}^{\circ}$ de Ocorrências & Porcentagem \\
\hline Oposição & 181 & $55,18 \%$ \\
\hline Oposição ao esperado & 65 & $19,82 \%$ \\
\hline Restrição & 64 & $19,51 \%$ \\
\hline Outros & 18 & $5,49 \%$ \\
\hline
\end{tabular}

LIVRO DE HISTÓRIAS (360 ocorrências)

\begin{tabular}{|l|l|l|}
\hline Relação de Sentido & $\mathrm{N}^{\circ}$ de Ocorrências & Porcentagem \\
\hline Oposição & 286 & $79,44 \%$ \\
\hline Oposição ao esperado & 38 & $10,55 \%$ \\
\hline Restrição & 25 & $6,94 \%$ \\
\hline Outros & 11 & $3,07 \%$ \\
\hline
\end{tabular}

POLÍTICA (159 ocorrências)

\begin{tabular}{|l|l|l|}
\hline Relação de Sentido & $\mathrm{N}^{\circ}$ de Ocorrências & Porcentagem \\
\hline Oposição & 104 & $65,41 \%$ \\
\hline Oposição ao esperado & 6 & $3,77 \%$ \\
\hline Restrição & 43 & $27,04 \%$ \\
\hline Outros & 6 & $3,78 \%$ \\
\hline
\end{tabular}

Com relação ao tipo de junção, os resultados foram os seguintes:

GERAL (847 ocorrências)

\begin{tabular}{|l|l|l|}
\hline Tipo de Junção & $\mathrm{N}^{\mathbf{o}}$ de Ocorrências & Porcentagem \\
\hline Correlativa & 102 & $12,04 \%$ \\
\hline Não correlativa & 745 & $87,96 \%$ \\
\hline
\end{tabular}

SARGENTO GETÚLIO (328 ocorrências)

\begin{tabular}{|l|l|l|}
\hline Tipo de Junção & $\mathrm{N}^{\mathbf{o}}$ de Ocorrências & Porcentagem \\
\hline Correlativa & 37 & $11,28 \%$ \\
\hline Não correlativa & 291 & $88,72 \%$ \\
\hline
\end{tabular}

LIVRO DE HISTÓRIAS (360 ocorrências)

\begin{tabular}{|l|l|l|}
\hline Tipo de Junção & $\mathrm{N}^{\mathbf{o}}$ de Ocorrências & Porcentagem \\
\hline Correlativa & 31 & $8,61 \%$ \\
\hline Não correlativa & 329 & $91,39 \%$ \\
\hline
\end{tabular}


POLÍTICA (159 ocorrências)

\begin{tabular}{|l|l|l|}
\hline Tipo de Junção & $\mathrm{N}^{\mathbf{o}}$ de Ocorrências & Porcentagem \\
\hline Correlativa & 34 & $21,38 \%$ \\
\hline Não correlativa & 125 & $78,62 \%$ \\
\hline
\end{tabular}

Podemos concluir, a partir do que foi observado, que:

a) A conjunção mas tende a ser muito mais usada com função coordenativa do que com função coesiva.

b) Ao que parece, a polaridade não exerce grande influência no uso da conjunção mas.

c) A conjunção mas é muito mais frequentemente usada para indicar $o$ posição pura e simples do que para indicar oposição ao esperado, restrição ou outros tipos de relação de sentido.

(d) O emprego da conjunção mas no tipo de junção correlativa é bastante raro (exceto com relação à linguagem didático-científica, em que a taxa de frequência torna-se um pouco mais alta: 21,38\%).

e) Como já foi dito, a conjunção mas só ocorre em posição inicial na frase.

\subsection{Contudo}

Foram encontradas 24 ocorrências da conjunção contudo, correspondendo a $2,65 \%$ do total, sendo 2 em Livro de histórias $(0,52 \%)$ e 22 em Política (11,28\%).

Com relação ao tipo de função, tivemos os seguintes resultados:

GERAL (24 ocorrências)

\begin{tabular}{|l|l|l|}
\hline Tipo de Função & $\mathrm{N}^{\mathbf{o}}$ de Ocorrências & Porcentagem \\
\hline Coordenativa & 1 & $4,17 \%$ \\
\hline Coesiva & 23 & $95,83 \%$ \\
\hline - introduz período & 19 & $79,17 \%$ \\
\hline - introduz parágrafo & 4 & $16,66 \%$ \\
\hline
\end{tabular}

LIVRO DE HISTÓRIAS (2 ocorrências)

\begin{tabular}{|l|l|l|}
\hline Tipo de Função & $\mathrm{N}^{\circ}$ de Ocorrências & Porcentagem \\
\hline Coesiva & 2 & $100 \%$ \\
\hline - introduz período & 1 & $50 \%$ \\
\hline - introduz parágrafo & 1 & $50 \%$ \\
\hline
\end{tabular}


POLÍTICA (22 ocorrências)

\begin{tabular}{|l|l|l|}
\hline Tipo de Função & $\mathrm{N}^{\mathbf{o}}$ de Ocorrências & Porcentagem \\
\hline Coordenativa & 1 & $4,55 \%$ \\
\hline Coesiva & 21 & $95,45 \%$ \\
\hline - introduz período & 18 & $81,82 \%$ \\
\hline - introduz parágrafo & 3 & $13,63 \%$ \\
\hline
\end{tabular}

Com relação à posição na frase, tivemos os seguintes resultados:

GERAL (24 ocorrências)

\begin{tabular}{|l|l|l|}
\hline Posição & $\mathrm{N}^{\mathbf{o}}$ de Ocorrências & Porcentagem \\
\hline Começo de Frase & 16 & $66,67 \%$ \\
\hline Meio de Frase & 8 & $33,33 \%$ \\
\hline
\end{tabular}

LIVRO DE HISTÓRIAS (2 ocorrências)

\begin{tabular}{|l|l|l|}
\hline Posição & $\mathrm{N}^{\circ}$ de Ocorrências & Porcentagem \\
\hline Começo de Frase & 2 & $100 \%$ \\
\hline
\end{tabular}

POLÍTICA (22 ocorrências)

\begin{tabular}{|l|l|l|}
\hline Posição & $\mathrm{N}^{\mathrm{o}}$ de Ocorrências & Porcentagem \\
\hline Começo de Frase & 14 & $63,64 \%$ \\
\hline Meio de Frase & 8 & $36,36 \%$ \\
\hline
\end{tabular}

Com respeito à polaridade, chegamos aos seguintes resultados:

GERAL (24 ocorrências)

\begin{tabular}{|l|l|l|}
\hline Tipo de Polaridade & $\mathrm{N}^{\mathrm{o}}$ de Ocorrências & Porcentagem \\
\hline Mesma polaridade & 16 & $66,67 \%$ \\
\hline Polaridades distintas & 8 & $33,33 \%$ \\
\hline
\end{tabular}

LIVRO DE HISTÓRIAS (2 ocorrências)

\begin{tabular}{|l|l|l|}
\hline Tipo de Polaridade & $\mathrm{N}^{\circ}$ de Ocorrências & Porcentagem \\
\hline Mesma polaridade & 1 & $50 \%$ \\
\hline Polaridades distintas & 1 & $50 \%$ \\
\hline
\end{tabular}

POLÍTICA (22 ocorrências)

\begin{tabular}{|l|l|l|}
\hline Tipo de Polaridade & $\mathrm{N}^{\mathrm{o}}$ de Ocorrências & Porcentagem \\
\hline Mesma polaridade & 15 & $68,18 \%$ \\
\hline Polaridades distintas & 7 & $31,82 \%$ \\
\hline
\end{tabular}

Quanto ao tipo de relação de sentido, os resultados a que se chegou foram: 
GERAL (24 ocorrências)

\begin{tabular}{|l|l|l|}
\hline Relação de Sentido & $\mathrm{N}^{\circ}$ de Ocorrências & Porcentagem \\
\hline Oposição & 2 & $8,33 \%$ \\
\hline Oposição ao esperado & 1 & $4,17 \%$ \\
\hline Restrição & 21 & $87,50 \%$ \\
\hline
\end{tabular}

LIVRO DE HISTÓRIAS (2 ocorrências)

\begin{tabular}{|l|l|l|}
\hline Relação de Sentido & $\mathrm{N}^{\mathbf{o}}$ de Ocorrências & Porcentagem \\
\hline Restrição & 2 & $100 \%$ \\
\hline
\end{tabular}

POLÍTICA (22 ocorrências)

\begin{tabular}{|l|l|l|}
\hline Relação de Sentido & $\mathrm{N}^{\circ}$ de Ocorrências & Porcentagem \\
\hline Oposição & 2 & $9,09 \%$ \\
\hline Oposição ao esperado & 1 & $4,54 \%$ \\
\hline Restrição & 19 & $86,37 \%$ \\
\hline
\end{tabular}

Por último, com relação ao tipo de junção, os resultados foram os seguintes:

GERAL (24 ocorrências)

\begin{tabular}{|l|l|l|}
\hline Tipo de Junção & $\mathrm{N}^{\mathbf{o}}$ de Ocorrências & Porcentagem \\
\hline Correlativa & 17 & $70,83 \%$ \\
\hline Não correlativa & 8 & $29,17 \%$ \\
\hline
\end{tabular}

LIVRO DE HISTÓRIAS (2 ocorrências)

\begin{tabular}{|l|l|l|}
\hline Tipo de Junção & $\mathrm{N}^{\mathbf{o}}$ de Ocorrências & Porcentagem \\
\hline Correlativa & 1 & $50 \%$ \\
\hline Não correlativa & 1 & $50 \%$ \\
\hline
\end{tabular}

POLÍTICA (22 ocorrências)

\begin{tabular}{|l|l|l|}
\hline Tipo de Junção & $\mathrm{N}^{\mathbf{o}}$ de Ocorrências & Porcentagem \\
\hline Correlativa & 16 & $72,73 \%$ \\
\hline Não correlativa & 6 & $27,27 \%$ \\
\hline
\end{tabular}

Como podemos observar, a conjunção contudo:

a) É normalmente usada com função coesiva, em vez de função coordenativa.

b) Tanto pode ser usada no começo quanto no meio da frase, embora seja mais usada no começo da frase.

c) Tanto pode ser usada com orações que têm a mesma polaridade que aquelas às quais a conjunção remete, quanto com orações de polaridades distintas, apesar de o primeiro caso ser mais comum que o segundo. 
d) É usada quase que exclusivamente para expressar a relação de sentido de restrição.

e) É usada geralmente para expressar uma correlação (junção correlativa) entre dois segmentos do discurso.

\subsection{Entretanto}

Houve 16 ocorrências da conjunção entretanto, correspondendo a 1,77\% do total, sendo 1 em Sargento Getúlio (0,3\%), 5 em Livro de histórias (1,32\%) e 10 em Política (5,13\%).

Com relação ao tipo de função, obtivemos os seguintes

GERAL (16 ocorrências)

\begin{tabular}{|l|l|l|}
\hline Tipo de Função & $\mathrm{N}^{\circ}$ de Ocorrências & Porcentagem \\
\hline Coordenativa & 1 & $6,25 \%$ \\
\hline Coesiva & 15 & $93,75 \%$ \\
\hline - introduz período & 12 & $75 \%$ \\
\hline - introduz parágrafo & 3 & $18,75 \%$ \\
\hline
\end{tabular}

SARGENTO Getúlio (1 ocorrência)

Função Coesiva - introduz período

LIVRO DE HISTÓRIAS (5 ocorrências)

\begin{tabular}{|l|l|l|}
\hline Tipo de Função & $\mathrm{N}^{\mathbf{o}}$ de Ocorrências & Porcentagem \\
\hline Coordenativa & 1 & $20 \%$ \\
\hline Coesiva & 4 & $80 \%$ \\
\hline - introduz período & 2 & $40 \%$ \\
\hline - introduz parágrafo & 2 & $40 \%$ \\
\hline
\end{tabular}

Política (10 ocorrências)

\begin{tabular}{|l|l|l|}
\hline Tipo de Função & $\mathrm{N}^{\circ}$ de Ocorrências & Porcentagem \\
\hline Função Coesiva & 10 & $100 \%$ \\
\hline - introduz período & 9 & $90 \%$ \\
\hline - introduz parágrafo & 1 & $10 \%$ \\
\hline
\end{tabular}

Com relação à posição na frase, chegamos aos resultados abaixo:

GERAL (16 ocorrências)

\begin{tabular}{|l|l|l|}
\hline Posição & $\mathrm{N}^{\circ}$ de Ocorrências & Porcentagem \\
\hline Começo de frase & 12 & $75 \%$ \\
\hline Meio de frase & 4 & $25 \%$ \\
\hline
\end{tabular}


SARGENTO GETÚLIO (1 ocorrência)

Meio de frase (na verdade, ocorre após a contração no em início de período)

LIVRO DE HISTÓRIAS (5 ocorrências)

\begin{tabular}{|l|l|l|}
\hline Posição & $\mathrm{N}^{\circ}$ de Ocorrências & Porcentagem \\
\hline Começo de frase & 5 & $100 \%$ \\
\hline
\end{tabular}

POLÍTICA (10 ocorrências)

\begin{tabular}{|l|l|l|}
\hline Posição & $\mathrm{N}^{\mathbf{o}}$ de Ocorrências & Porcentagem \\
\hline Começo de frase & 7 & $70 \%$ \\
\hline Meio de frase & 3 & $30 \%$ \\
\hline
\end{tabular}

Com respeito ao tipo de polaridade, os resultados foram os seguintes:

GERAL (16 ocorrências)

\begin{tabular}{|l|l|l|}
\hline Tipo de Polaridade & $\mathrm{N}^{\mathbf{o}}$ de Ocorrências & Porcentagem \\
\hline Mesma polaridade & 10 & $62,5 \%$ \\
\hline Polaridades distintas & 6 & $37,5 \%$ \\
\hline
\end{tabular}

SARGENTO GETÚLIO (1 ocorrência)

Polaridades distintas

LIVRO DE HISTÓRIAS (5 ocorrências).

\begin{tabular}{|l|l|l|}
\hline Tipo de Polaridade & $\mathrm{N}^{\circ}$ de Ocorrências & Porcentagem \\
\hline Mesma polaridade & 3 & $60 \%$ \\
\hline Polaridades distintas & 2 & $40 \%$ \\
\hline
\end{tabular}

POLÍTICA (10 ocorrências).

\begin{tabular}{|l|l|l|}
\hline Tipo de Polaridade & $\mathrm{N}^{\mathrm{o}}$ de Ocorrências & Porcentagem \\
\hline Mesma polaridade & 7 & $70 \%$ \\
\hline Polaridades distintas & 3 & $30 \%$ \\
\hline
\end{tabular}

Com relação ao tipo de relação de sentido, os resultados foram os seguintes:

GERAL (16 ocorrências).

\begin{tabular}{|l|l|l|}
\hline Relação de Sentido & $\mathrm{N}^{\mathrm{o}}$ de Ocorrências & Porcentagem \\
\hline Oposição & 2 & $12,50 \%$ \\
\hline Oposição ao esperado & 3 & $18,75 \%$ \\
\hline Restrição & 11 & $68,75 \%$ \\
\hline
\end{tabular}


SARGENTO GETÚLIO (1 ocorrência).

Oposição ao esperado

LIVRO DE HISTÓRIAS (5 ocorrências).

\begin{tabular}{|l|l|l|}
\hline Relação de Sentido & $\mathrm{N}^{\circ}$ de Ocorrências & Porcentagem \\
\hline Oposição & 1 & $20 \%$ \\
\hline Oposição ao esperado & 1 & $20 \%$ \\
\hline Restrição & 3 & $60 \%$ \\
\hline
\end{tabular}

POLÍTICA (10 ocorrências).

\begin{tabular}{|l|l|l|}
\hline Relação de Sentido & $\mathrm{N}^{\circ}$ de Ocorrências & Porcentagem \\
\hline Oposição & 1 & $10 \%$ \\
\hline Oposição ao esperado & 1 & $10 \%$ \\
\hline Restrição & 8 & $80 \%$ \\
\hline
\end{tabular}

Quanto ao tipo de junção, chegamos aos seguintes resultados:

GERAL (16 ocorrências)

\begin{tabular}{|l|l|l|}
\hline Tipo de Junção & $\mathrm{N}^{\mathbf{o}}$ de Ocorrências & Porcentagem \\
\hline Correlativa & 1 & $6,25 \%$ \\
\hline Não correlativa & 15 & $93,75 \%$ \\
\hline
\end{tabular}

SARGENTO GETÚLIO (1 ocorrência)

Não correlativa

LIVRO DE HISTÓRIAS (5 ocorrências)

\begin{tabular}{|l|l|l|}
\hline Tipo de Junção & $\mathrm{N}^{\mathbf{o}}$ de Ocorrências & Porcentagem \\
\hline Não correlativa & 5 & $100 \%$ \\
\hline
\end{tabular}

POLÍTICA (10 ocorrências)

\begin{tabular}{|l|l|l|}
\hline Tipo de Junção & $\mathrm{N}^{\mathbf{o}}$ de Ocorrências & Porcentagem \\
\hline Correlativa & 1 & $10 \%$ \\
\hline Não correlativa & 9 & $90 \%$ \\
\hline
\end{tabular}

A partir do que foi exposto, chegamos às conclusões abaixo, em relação à conjunção entretanto:

a) A sua função é quase sempre coesiva.

b) $\mathrm{O}$ fator polaridade parece não ser de importância para sua utilização.

c) Sua relação de sentido primordial é a de restrição.

d) Sua posição é geralmente no início da frase. 
e) Sua junção é, com raras exceções, não correlativa.

\subsection{Porém}

A conjunção porém ocorre 15 vezes no "corpus", correspondendo a $1,65 \%$ do total, sendo 4 em Sargento Getúlio (equivalente a 1,20\%), 10 em Livro de histórias $(2,64 \%)$ e 1 em Política $(0,51 \%)$.

Com relação ao tipo de função, os resultados a que se chegou foram:

GERAL (15 ocorrências)

\begin{tabular}{|l|l|l|}
\hline Tipo de Função & $\mathrm{N}^{\circ}$ de Ocorrências & Porcentagem \\
\hline Coordenativa & 7 & $46,67 \%$ \\
\hline Coesiva & 8 & $53,33 \%$ \\
\hline - introduz período & 6 & $40 \%$ \\
\hline - introduz parágrafo & 2 & $13,33 \%$ \\
\hline
\end{tabular}

SARGENTO GETÚLIO (4 ocorrências)

\begin{tabular}{|l|l|l|}
\hline Tipo de Função & $\mathrm{N}^{\mathbf{o}}$ de Ocorrências & Porcentagem \\
\hline Coordenativa & 3 & $75 \%$ \\
\hline Coesiva & 1 & $25 \%$ \\
\hline
\end{tabular}

LIVRO DE HISTÓRIAS (10 ocorrências)

\begin{tabular}{|l|l|l|}
\hline Tipo de Função & $\mathrm{N}^{\mathbf{o}}$ de Ocorrências & Porcentagem \\
\hline Coordenativa & 4 & $40 \%$ \\
\hline Coesiva & 6 & $60 \%$ \\
\hline - introduz período & 5 & $50 \%$ \\
\hline - introduz parágrafo & 1 & $10 \%$ \\
\hline
\end{tabular}

POLÍTICA (1 ocorrência)

Função Coesiva - introduz parágrafo

Quanto à posição na frase, tivemos os resultados abaixo:

GERAL (15 ocorrências)

\begin{tabular}{|l|l|l|}
\hline Posição & $\mathrm{N}^{\circ}$ de Ocorrências & Porcentagem \\
\hline Começo da frase & 11 & $73,33 \%$ \\
\hline Meio de frase & 4 & $26,67 \%$ \\
\hline
\end{tabular}

SARGENTO GETÚLIO (4 ocorrências)

\begin{tabular}{|l|l|l|}
\hline Posição & $\mathrm{N}^{\mathbf{o}}$ de Ocorrências & Porcentagem \\
\hline Começo de frase & 1 & $25 \%$ \\
\hline Meio de frase & 3 & $75 \%$ \\
\hline
\end{tabular}




\section{FACULDADE DE FORMAÇÃo dE PROFESSORES}

Obs.: É importante notar, no entanto, que a conjunção porém que ocorre em começo de frase, ocorre após a conjunção mas.

LIVRO DE HISTÓRIAS (10 ocorrências)

\begin{tabular}{|l|l|l|}
\hline Posição & $\mathrm{N}^{\circ}$ de Ocorrências & Porcentagem \\
\hline Começo de frase & 9 & $90 \%$ \\
\hline Meio de frase & 1 & $10 \%$ \\
\hline
\end{tabular}

POLÍTICA (1 ocorrência)

Meio de frase

Quanto ao tipo de polaridade, os resultados foram os seguintes:

GERAL (15 ocorrências)

\begin{tabular}{|l|l|l|}
\hline Tipo de Polaridade & $\mathrm{N}^{\mathbf{o}}$ de Ocorrências & Porcentagem \\
\hline Mesma polaridade & 11 & $73,33 \%$ \\
\hline Polaridades distintas & 4 & $26,67 \%$ \\
\hline
\end{tabular}

SARGENTO GETÚLIO (4 ocorrências)

\begin{tabular}{|l|l|l|}
\hline Tipo de Polaridade & $\mathrm{N}^{\mathbf{o}}$ de Ocorrências & Porcentagem \\
\hline Mesma polaridade & 4 & $100 \%$ \\
\hline
\end{tabular}

LIVRO DE HISTÓRIAS (10 ocorrências)

\begin{tabular}{|l|l|l|}
\hline Tipo de Polaridade & $\mathrm{N}^{\mathbf{o}}$ de Ocorrências & Porcentagem \\
\hline Mesma polaridade & 6 & $60 \%$ \\
\hline Polaridades distintas & 4 & $40 \%$ \\
\hline
\end{tabular}

POLÍTICA (1 ocorrência)

Mesma polaridade

Quanto ao tipo de relação de sentido, os resultados foram:

GERAL (15 ocorrências)

\begin{tabular}{|l|l|l|}
\hline Relação de Sentido & $\mathrm{N}^{\circ}$ de Ocorrências & Porcentagem \\
\hline Oposição & 1 & $6,67 \%$ \\
\hline Oposição ao esperado & 5 & $33,33 \%$ \\
\hline Restrição & 9 & $60 \%$ \\
\hline
\end{tabular}

SARGENTO GETÚLIO (4 ocorrências)

\begin{tabular}{|l|l|l|}
\hline Relação de Sentido & $\mathrm{N}^{\mathrm{o}}$ de Ocorrências & Porcentagem \\
\hline Oposição & 1 & $25 \%$ \\
\hline Oposição ao esperado & 1 & $25 \%$ \\
\hline Restrição & 2 & $50 \%$ \\
\hline
\end{tabular}


LIVRO DE HISTÓRIAS (10 ocorrências)

\begin{tabular}{|l|l|l|}
\hline Relação de Sentido & $\mathrm{N}^{\circ}$ de Ocorrências & Porcentagem \\
\hline Oposição ao esperado & 4 & $40 \%$ \\
\hline Restrição & 6 & $60 \%$ \\
\hline
\end{tabular}

POLÍTICA (1 ocorrência)

Restrição

Em relação ao tipo de junção, chegou-se aos resultados abaixo:

GERAL (15 ocorrências)

\begin{tabular}{|l|l|l|}
\hline Tipo de Junção & $\mathrm{N}^{\mathbf{o}}$ de Ocorrências & Porcentagem \\
\hline Correlativa & 3 & $20 \%$ \\
\hline Não correlativa & 12 & $80 \%$ \\
\hline
\end{tabular}

SARGENTO GETÚLIO (4 ocorrências)

\begin{tabular}{|l|l|l|}
\hline Tipo de Junção & $\mathrm{N}^{\mathbf{o}}$ de Ocorrências & Porcentagem \\
\hline Correlativa & 2 & $50 \%$ \\
\hline Não correlativa & 2 & $50 \%$ \\
\hline
\end{tabular}

LIVRO DE HISTÓRIAS (10 ocorrências)

\begin{tabular}{|l|l|l|}
\hline Tipo de Junção & $\mathrm{N}^{\mathbf{o}}$ de Ocorrências & Porcentagem \\
\hline Correlativa & 1 & $10 \%$ \\
\hline Não correlativa & 9 & $90 \%$ \\
\hline
\end{tabular}

POLÍTICA (1 ocorrência)

Não correlativa

Podemos concluir, com relação à conjunção porém, que:

a) O tipo de função parece não ter importância para o emprego da conjunção porém, visto as porcentagens serem quase as mesmas.

b) A posição preferencial da conjunção porém é no começo da frase.

c) É mais comum o uso da conjunção porém com sentenças que têm a mesma polaridade que aquelas a que remetem.

d) É muito raro o emprego da conjunção porém em sentenças que expressam oposição.

e) É menos comum o uso da conjunção porém com sentenças correlativas do que com sentenças não correlativas. 


\subsection{No entanto}

Houve 4 ocorrências da conjunção no entanto, correspondendo a 0,44\% do total, sendo 1 em Livro de histórias $(0,26 \%)$ e 3 em Política $(1,54 \%)$. Não houve sequer uma ocorrência a da conjunção no entanto em Sargento Getúlio.

Com relação ao tipo de função, os resultados foram os seguintes:

GERAL (4 ocorrências)

\begin{tabular}{|l|l|l|}
\hline Tipo de Função & $\mathrm{N}^{\mathrm{o}}$ de Ocorrências & Porcentagem \\
\hline Coordenativa & 1 & $25 \%$ \\
\hline Coesiva & 3 & $75 \%$ \\
\hline - introduz período & 1 & $25 \%$ \\
\hline - introduz parágrafo & 2 & $50 \%$ \\
\hline
\end{tabular}

LIVRO DE HISTÓRIAS (1 ocorrência)

Função Coesiva - introduz parágrafo

POLÍTICA (3 ocorrências)

\begin{tabular}{|l|l|l|}
\hline Tipo de Função & $\mathrm{N}^{\mathbf{o}}$ de Ocorrências & Porcentagem \\
\hline Coordenativa & 1 & $33,33 \%$ \\
\hline Coesiva & 2 & $66,66 \%$ \\
\hline - introduz período & 1 & $33,33 \%$ \\
\hline - introduz parágrafo & 1 & $33,33 \%$ \\
\hline
\end{tabular}

Com relação à posição na frase, os resultados foram:

GERAL (4 ocorrências)

\begin{tabular}{|l|l|l|}
\hline Posição & $\mathrm{N}^{\circ}$ de Ocorrências & Porcentagem \\
\hline Começo de frase & 3 & $75 \%$ \\
\hline Meio de frase & 1 & $25 \%$ \\
\hline
\end{tabular}

LIVRO DE HISTÓRIAS (1 ocorrência)

Começo de frase

POLÍTICA (3 ocorrências)

\begin{tabular}{|l|l|l|}
\hline Posição & $\mathrm{N}^{\circ}$ de Ocorrências & Porcentagem \\
\hline Começo de frase & 2 & $66,66 \%$ \\
\hline Meio de frase & 1 & $33,33 \%$ \\
\hline
\end{tabular}

No tocante ao tipo de polaridade, todas as ocorrências da conjunção no entanto introduziam sentenças com a mesma polaridade que a sentença à qual remetiam. 
Em relação ao tipo de relação de sentido, os resultados foram os que se seguem:

GERAL (4 ocorrências)

\begin{tabular}{|l|l|l|}
\hline Relação de Sentido & $\mathrm{N}^{\circ}$ de Ocorrências & Porcentagem \\
\hline oposição ao esperado & 1 & $25 \%$ \\
\hline Restrição & 3 & $75 \%$ \\
\hline
\end{tabular}

LIVRO DE HISTÓRIAS (1 ocorrência)

Restrição

POLÍTICA (3 ocorrências)

\begin{tabular}{|l|l|l|}
\hline Relação de Sentido & $\mathrm{N}^{\mathbf{o}}$ de Ocorrências & Porcentagem \\
\hline Oposição ao esperado & 1 & $33,33 \%$ \\
\hline Restrição & 2 & $66,66 \%$ \\
\hline
\end{tabular}

No que diz respeito ao tipo de junção, chegou-se aos resultados abaixo:

GERAL (4 ocorrências)

\begin{tabular}{|l|l|l|}
\hline Tipo de Junção & $\mathrm{N}^{\circ}$ de Ocorrências & Porcentagem \\
\hline Correlativa & 1 & $25 \%$ \\
\hline Não correlativa & 3 & $75 \%$ \\
\hline
\end{tabular}

LIVRO DE HISTÓRIAS (1 ocorrência)

Não correlativa

POLÍTICA (3 ocorrências)

\begin{tabular}{|l|l|l|}
\hline Tipo de Junção & $\mathrm{N}^{\mathbf{o}}$ de Ocorrências & Porcentagem \\
\hline Correlativa & 1 & $33,33 \%$ \\
\hline Não correlativa & 2 & $66,66 \%$ \\
\hline
\end{tabular}

As conclusões a que se chegou com relação à conjunção no entanto foram:

a) Ao que parece, ela tende a ser usada mais com função coesiva do que com função coordenativa.

b) Também parece ser preferencialmente empregada em começo de frase.

c) Tudo indica que ela introduz exclusivamente sentenças com a mesma polaridade que a daquelas às quais remete.

d) Parece não ser empregada para expressar oposição pura e simples e ser raramente empregada para expressar a oposição ao esperado. 


\section{FACULDADE DE FormaÇÃo de PROFESSORES}

e) Determina normalmente um tipo de junção não correlativa.

Cabe ressaltar, no entanto, que o reduzido número de ocorrências não nos permite conclusões realmente precisas.

\section{Conclusão}

Com base no que foi pesquisado, podemos afirmar que:

a) A conjunção mas, como era de se esperar, detém uma supremacia quase que absoluta sobre as demais conjunções adversativas (entre $98,50 \% \mathrm{e}$ $81,54 \%)$.

b) Talvez a supremacia da conjunção mas se deva ao fato dela ser praticamente a única usada na modalidade mais popular da língua (isto é, menos cuidada), o que faria com que recorrêssemos a ela sempre que não estivéssemos diretamente preocupados com a linguagem (na linguagem descuidada de Sargento Getúlio, ocorrem 328 exemplos da conjunção mas contra apenas 5 exemplos de outras conjunções).

c) Uma outra explicação para tal supremacia seria o fato da conjunção mas expressar prioritariamente a relação de sentido oposição pura e simples, a qual é muito mais frequente que as outras relações de sentido (entre $75,92 \%$ e 54,87\%, em relação à soma das outras relações de sentido).

d) Uma terceira explicação seria o fato da conjunção mas implicar, na maioria das vezes, função coordenativa (entre $75,55 \%$ e $69,18 \%$ ), sendo o emprego de conjunções adversativas com função coordenativa muito mais frequente que seu emprego com função coesiva (entre $73,28 \%$ e $57,43 \%$ das ocorrências foram coordenativas).

e) A posição padrão da conjunção adversativa no português contemporâneo do Brasil é, salvo exceções, no começo da frase: para um total de 906 ocorrências, houve apenas 16 casos $(1,77 \%)$ em que a conjunção se encontrava em meio de frase e não houve sequer um em que estivesse no final da frase.

f) A polaridade parece não ter influência no uso das conjunções adversativas, embora haja uma ligeira predominância de sentenças com a mesma polaridade que aquelas às quais a conjunção remete (entre $65,87 \%$ e $52,25 \%)$.

g) O tipo de junção que se estabelece entre as sentenças introduzidas pela conjunção adversativa e a porção de texto à qual elas remetem é quase 
sempre não correlativa (entre $91,27 \%$ e $73,33 \%$ ). Tal fato, no entanto, dependerá muito do tipo de conjunção empregado, como vimos anteriormente.

h) As conjunções contudo e entretanto, por um lado, e porém, por outro lado, têm um comportamento diametralmente oposto: enquanto a frequência de contudo e entretanto vai aumentando conforme a linguagem vai ficando mais cuidada (de 0\% e 0,3\% em Sargento Getúlio para $11,28 \%$ e $5,13 \%$ em Política), a frequência de porém vai diminuindo (de 1,2\% em Sargento Getúlio para 0,51\% em Política), e vice-versa.

i) A diferença básica entre contudo e entretanto parece estar no fato da primeira estabelecer um tipo de junção primordialmente correlativo (entre $70,83 \%$ a $72,73 \%$ ), enquanto a segunda determina quase que exclusivamente uma junção não correlativa (entre $90 \%$ e 93,75\%).

j) As conjunções porém, contudo, entretanto e no entanto (quer dizer, todas exceto mas) expressam, na maioria das vezes, a relação de sentido restrição (entre $60 \%$ e $87,50 \%$ ).

k) Os números referentes à conjunção no entanto não nos permitiram chegar a conclusões acerca dela, exceto que ela é raramente usada no português escrito contemporâneo do Brasil.

\section{REFERÊNCIAS BIBLIOGRÁFICAS}

CAMARA JR, J. Mattoso. Dicionário de linguística e gramática. 10. ed. Petrópolis: Vozes, 1981.

HALLIDAY, M. A. K. Introduction to functional grammar. Londres: Edward Arnold, 1985.

1979.

; HASAN, Ruqaya. Cohesion in English. Londres: Longman,

MARQUES, Maria H. D. Iniciação à semântica. Rio de Janeiro: Jorge Zahar, 1990.

RIBEIRO, J. Ubaldo. Sargento Getúlio. Rio de Janeiro: Nova Fronteira, 1982. . Livro de histórias. São Paulo Círculo do Livro, 1986. . Política. Rio de Janeiro: Nova Fronteira, 1986. 